\title{
Delays to Hospital Presentation in Women and Men with ST-Segment Elevation Myocardial Infarction: A Multi-Center Analysis of Patients Hospitalized in New York City
}

\author{
David Weininger' \\ Juan Pablo Cordova ${ }^{2}$ \\ Eelin Wilson $^{3}$ \\ Dayana J Eslava ${ }^{4}$ \\ Carlos L Alviar ${ }^{5}$ \\ Aleksandr Korniyenko ${ }^{6}$ \\ Chirag Pankajkumar Bavishi ${ }^{7}$ \\ Mun $\mathrm{K} \mathrm{Hong}^{8}$ \\ Amy Chorzempa 9 \\ John Fox ${ }^{10}$ \\ Jacqueline E Tamis-Holland ${ }^{4}{ }^{4}$ \\ 'Westchester Medical Center, Valhalla, \\ NY, USA; ${ }^{2}$ Southshore Cardiovascular \\ Associates, Tampa, FL, USA; ${ }^{3}$ Montefiore \\ Medical Center, New York, NY, USA; \\ ${ }^{4}$ Mount Sinai Morningside Hospital, \\ New York, NY, USA; ${ }^{5}$ NYU Medical \\ Center and Bellevue Hospital Center, \\ New York, NY, USA; ${ }^{6}$ Univeristy of Texas \\ Health, Tyler, TX, USA; ${ }^{7}$ University of \\ Missouri Health Care, Columbia, MO, \\ USA; ${ }^{8}$ Bassett Healthcare Network, \\ Cooperstown, NY, USA; ${ }^{9}$ Massachusetts \\ General Hospital, Boston, MA, USA; \\ ${ }^{10}$ Mount Sinai Beth Israel Hospital, \\ New York, NY, USA
}

Purpose: Previous studies have shown longer delays from symptom onset to hospital presentation (S2P time) in women than men with acute myocardial infarction. The aim of this study is to understand the reasons for delays in seeking care among women and men presenting with an ST-Segment Elevation Myocardial Infarction (STEMI) through a detailed assessment of the thoughts, perceptions and patterns of behavior.

Patients/Methods and Results: A total of 218 patients with STEMI treated with primary angioplasty at four New York City Hospitals were interviewed (24\% female; Women: $68.7 \pm$ 13.1 years and men: $60.7 \pm 13.8$ years) between January 2009 and August 2012. A significantly larger percentage of women than men had no chest pain $(62 \%$ vs $36 \%$, $\mathrm{p}<0.01)$. Compared to men, a smaller proportion of women thought they were having a myocardial infarction $(15 \%$ vs $34 \%, \mathrm{p}=0.01)$. A larger proportion of women than men had S2P time $>90$ minutes $(72 \%$ of women vs $54 \%$ of men, $\mathrm{p}=0.03)$. Women were more likely than men to hesitate before seeking help, and more women than men hesitated because they did not think they were having an AMI $(91 \%$ vs $83 \%, \mathrm{p}=0.04)$. Multivariate regression analysis showed that female sex (Odds Ratio: 2.46, 95\% CI 1.10-5.60 $\mathrm{P}=0.03$ ), subjective opinion it was not an AMI (Odds Ratio 2.44, 95\% CI 1.20-5.0, P=0.01) and level of education less than high school (Odds ratio 7.21 95\% CI 1.59-32.75 $\mathrm{P}=0.01$ ) were independent predictors for $\mathrm{S} 2 \mathrm{P}>90$ minutes.

Conclusion: Women with STEMI have longer pre-hospital delays than men, which are associated with a higher prevalence of atypical symptoms and a lack of belief in women that they are having an AMI. Greater focus should be made on educating women (and men) regarding the symptoms of STEMI, and the importance of a timely response to these symptoms.

Keywords: women, awareness, acute myocardial infarction, symptoms
Correspondence: Jacqueline E

Tamis-Holland

$\mathrm{Tel}+\mathrm{I} 212-523-2400$

Fax +1 212-523-5226

Email Jacqueline.Tamis-

Holland@MountSinai.org

\section{Introduction}

Reducing total ischemic time in patients presenting with an acute ST segment elevation myocardial infarction (STEMI) remains an important focus of healthcare systems worldwide. Total ischemic time is the sum of symptom onset to presentation times (S2P time) and first medical contact to device time. The American College of Cardiology/American Heart Association (ACCF/AHA) guidelines recommend a first medical contact to device time of less than 90 minutes $^{1}$ in an effort to reduce total ischemic time. As a result of nationwide efforts to create 
systems of care to better manage patients with STEMI, there have been improvements in this metric over time. ${ }^{2-4}$ Unfortunately, despite improvements in treatment times, patient delays remain an important obstacle to timely reperfusion, with little improvement in S2P times over the years. ${ }^{5-8}$ This is important because longer S2P times have been associated with lower use of reperfusion therapies and higher mortality. ${ }^{7,9-14}$ Studies have found that various factors are associated with a longer S2P time, including among other things age, sex, race/ethnicity, level of education, insurance status and absence of use of emergency medical services (EMS)..$^{5-9,12,15-25}$ Multiple studies have shown that female sex is an independent predictor of pre-hospital delay. ${ }^{5,6,8,9,12,16,17,26,27}$ However, fewer studies have explored the reasons for this delay, and it is not known whether this delay among women relates to an atypical presentation without chest pain, which is also more common in women, ${ }^{22,28-30}$ a lack of awareness of symptoms, or whether there are other socio-demographic variables at play. This helpful meta-synthesis ${ }^{31}$ analyzed qualitative data from multiple and varied studies and was able to build new theories of why there is a delay in women as compared to men. However, most of the studies exploring the reason for delay to presentation have been performed before the introduction of the Red Dress campaign or MISSION: Lifeline and, unlike these earlier studies, we specifically chose to focus our analysis on a population of patients with STEMI undergoing primary percutaneous coronary intervention (PCI), which are the exact group of patients in whom timely presentation is critical.

We sought to understand the reasons for delay in women and men with acute myocardial infarction (AMI) through a detailed assessment of the thoughts, perceptions and patterns of behavior among patients presenting with an acute STEMI referred for primary PCI.

\section{Methods}

\section{Study Design}

We examined consecutive patients referred for primary angioplasty for the treatment of an acute STEMI at four New York City Hospitals (St Luke's Hospital, Roosevelt Hospital, Beth Israel Medical Center, and Long Island College Hospital) between January 2009 and August 2012. We used a prospective database of patients with STEMI undergoing primary PCI to identify patients eligible for recruitment. As part of routine care, patients at all institutions were routinely contacted after discharge. At the time of these follow-up calls, patients were approached to participate in the current study. If they were agreeable to participate in the additional telephone interview, telephone consent was obtained. All patients referred for primary angioplasty who were available for follow-up telephone interviews were included in the study. Patients unable or unwilling to consent to telephone interviews were excluded from the study. In addition, patients were also excluded from the study if there was insufficient information regarding the timing of symptom onset, and the time to treatment, or if the AMI developed while in the hospital or if the patient did not undergo primary PCI. The protocol (including the approval of obtaining verbal consent to participate in the telephone interviews) and the scripted telephone interviews were approved by the Institutional Review Board at all participating hospitals.

Routine phone calls were conducted as a follow-up post AMI assessment performed at each hospital. For the purposes of the current study, in order to collect the answer to the additional questions, the calls conducted during the set time period were performed by resident physicians. At the time of these telephone calls, patients were asked whether they would be willing to answer additional questions as part of an institutional review board approved study. We allowed for open ended responses so that patients might express their thoughts at the moment and not limit their reasoning to a set of limited options. Blinded responses were reviewed and aggregated into groups by the team of doctors conducting the interviews. These blinded responses were then reviewed and approved by the lead investigator.

\section{Data Collection and Telephone Surveys}

Baseline clinical and demographic data, as well as S2P times were obtained from a prospective registry of cardiac catheterization lab patients. S2P time was prospectively collected at the time of initial evaluation and based on the patient's account of the onset of symptoms reported to the medical staff on the day of the incident infarction. Following discharge from the hospital, telephone interviews were conducted to assess patterns of behavior during the incident infarction. Patients were required to provide telephone consent for said interviews. Telephone interviews were conducted in the patient's native language (Spanish, Russian, Chinese, and Polish) by researchers fluent in these languages. The protocol encouraged that when possible telephone interviews be conducted within 
one month of discharge. The survey consisted of 19 open ended questions. Questions included inquiries regarding socio-demographic related matters, description of symptoms, interpretation of said symptoms at the time of the event, and actions following the onset of symptoms (Supplemental Figure 1).

\section{Statistical Analysis}

Baseline clinical variables and behavioral characteristics were compared by sex. Student's two tailed T tests were used to compare continuous variables and chi square tests were used to test associations between categorical variables. Subsequently we looked at demographic, clinical and behavioral variables to determine which variables predicted a delay to hospital presentation. We defined a delayed presentation as an S2P time that was over 90 minutes. Univariate and multivariate logistic regression analyses were then performed to determine which variables were independently associated with a delayed hospital presentation. We used fixed effect logistic regression model to analyze the predictors of delayed S2P time. We included the clinically relevant variables associated with a prolonged S2P time and the variables that were significantly different by sex into the multivariate analysis: These included age, sex, presence of diabetes, race, level of education, insurance status, employment status, atypical symptoms and subjective opinion the event was not an AMI. Analyses were performed using SPSS 19.0 software.

\section{Results}

Among 218 patients examined, 53 (24\%) were female. Table 1 depicts the baseline demographic and clinical variables for women and men. Women were older than men and significantly more likely to have a history of hypertension and diabetes. A larger proportion of women than men were black. Women were less likely than men to be active smokers and fewer women than men achieved a higher level of education (college degree and above). A similar proportion of men and women had a myocardial infarction in the past (12\% of women and $13 \%$ of men) but a higher proportion of women had a prior CVA ( $10 \%$ of women and $5 \%$ of men) without being statistically significant $(\mathrm{p}=0.8)$. Prior revascularization was also more common in men $(17 \%)$ than in women $(9 \%)$ but was also not statistically significant $(\mathrm{p}<0.2)$.

Symptoms at the time of the infarction and behavioral characteristics during the incident event for women and men are depicted in Table 2. A significantly larger proportion of women than men had atypical symptoms (absence
Table I Baseline Clinical and Demographic Variables

\begin{tabular}{|c|c|c|c|}
\hline Variable & $\begin{array}{l}\text { Women } \\
(n=53)\end{array}$ & $\begin{array}{c}\text { Men } \\
(n=165)\end{array}$ & p-value \\
\hline $\begin{array}{l}\text { Mean age ( } \pm \text { standard } \\
\text { deviation) }\end{array}$ & $68.7(13.1)$ & $60.7(13.8)$ & $<0.01$ \\
\hline Hypertension & $68 \%$ & $63 \%$ & $<0.01$ \\
\hline Diabetes Mellitus & $26 \%$ & $13 \%$ & 0.04 \\
\hline Prior Myocardial Infarction & $12 \%$ & $13 \%$ & 0.8 \\
\hline Prior Revascularization & $9 \%$ & $17 \%$ & $<0.2$ \\
\hline $\begin{array}{l}\text { Prior Cerebrovascular } \\
\text { Accident }\end{array}$ & $10 \%$ & $5 \%$ & 0.8 \\
\hline Current Smoker & $15 \%$ & $23 \%$ & 0.43 \\
\hline Nighttime presentation & $22 \%$ & $30 \%$ & 0.29 \\
\hline Hispanic Ethnicity & $32 \%$ & $25 \%$ & 0.49 \\
\hline $\begin{array}{l}\text { Race } \\
\text { White } \\
\text { Black } \\
\text { Other }\end{array}$ & $\begin{array}{c}55 \% \\
42 \% \\
3 \%\end{array}$ & $\begin{array}{l}67 \% \\
22 \% \\
11 \%\end{array}$ & 0.01 \\
\hline $\begin{array}{l}\text { Education } \\
\text { College diploma and } \\
\text { above } n(\%) \\
\text { High School diploma } \\
\text { n (\%) } \\
\text { No High School Diploma } \\
\text { n (\%) }\end{array}$ & $\begin{array}{r}15 \% \\
79 \% \\
6 \%\end{array}$ & $\begin{array}{r}49 \% \\
45 \% \\
6 \%\end{array}$ & $<0.01$ \\
\hline Uninsured n (\%) & $25 \%$ & $11 \%$ & 0.91 \\
\hline $\begin{array}{l}\text { Employment Status } \\
\text { Employed n (\%) } \\
\text { Unemployed n (\%) } \\
\text { Retired n (\%) } \\
\text { Disabled n (\%) }\end{array}$ & $\begin{array}{c}23 \% \\
31 \% \\
46 \% \\
0 \%\end{array}$ & $\begin{array}{c}46 \% \\
23 \% \\
31 \% \\
0 \%\end{array}$ & 0.04 \\
\hline
\end{tabular}

of chest pain). As compared with men, women were less likely to realize they were having an AMI (15\% vs $34 \%$, $\mathrm{p}=<0.01)$ and more likely to admit that they hesitated before seeking help ( $81 \%$ vs $61 \% \mathrm{P}<0.01)$. Women were more likely than men to call a family or friend (51\% vs $36 \% \mathrm{p}<0.05)$. Among patients with atypical symptoms, only $12(13 \%)$ thought they were having an AMI. This finding was numerically lower in women than men ( $6 \%$ vs $17 \%, \mathrm{p}=0.14)$. Time of presentation was not significant as nighttime AMI (between 6:00pm and 6:00am) accounted for $22 \%$ of the AMI in women and $30 \%$ of the AMI in men $(\mathrm{p}=0.29)$. 
Table 2 Thoughts and Actions Prior to Hospital Arrival

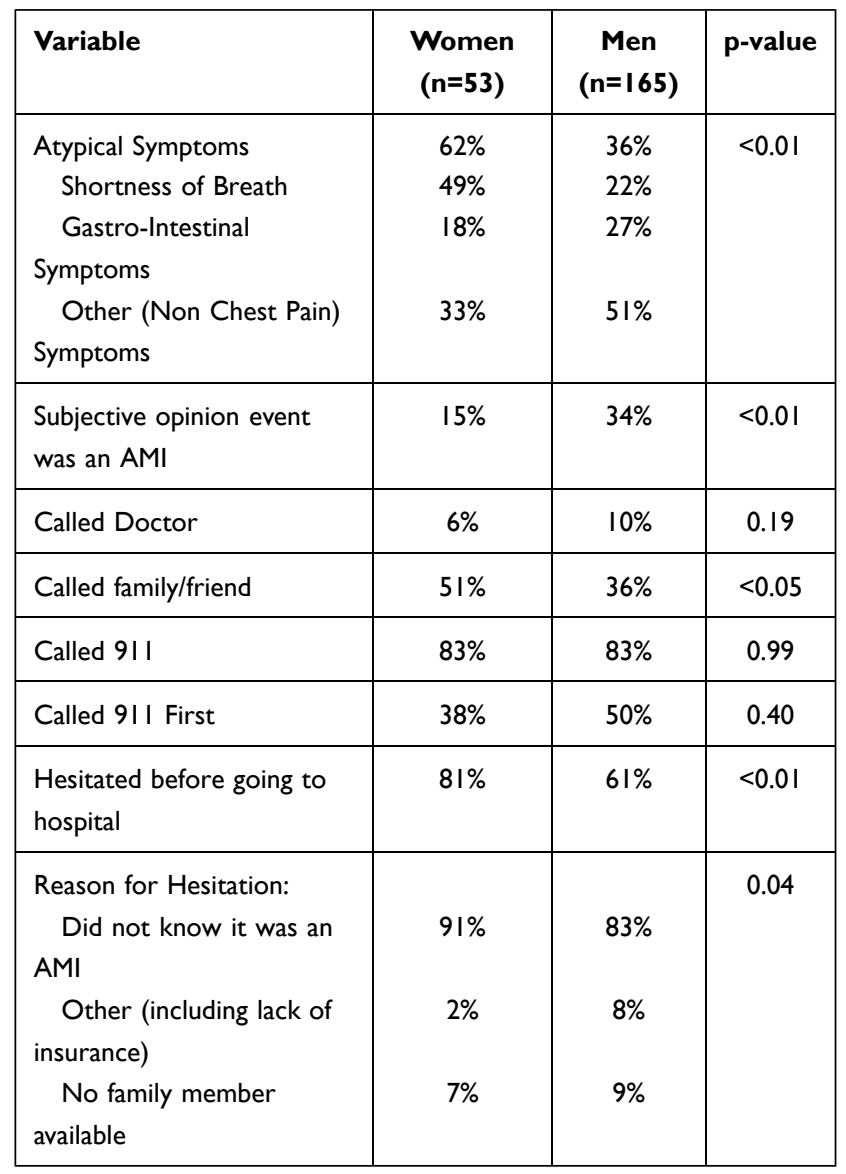

Abbreviation: AMI, Acute Myocardial Infarction.

The mean $\mathrm{S} 2 \mathrm{P}$ time was 241.48 minutes (range 0 to 4320 minutes), the median was $109 \mathrm{~min}$ and the mode 62 min. There were no significant differences in the mean S2P time by sex, [267.38 minutes vs 233.11 minutes, $\mathrm{p}=0.3$, however a larger proportion of women than men had S2P time $>90$ minutes $(72 \%$ vs $54 \%$, p-value $=0.03)$. Among patients with atypical symptoms, a larger percentage of women than men presented more than 90 minutes after symptom onset ( $45 \%$ vs $19 \%$, p-value $<0.01)$. The mean D2B time was similar in women and men as was the proportion of women and men with a D2B over 90 minutes. The mean total ischemic time was similar in women and men $375.8 \pm 338.6$ minutes vs $326.0 \pm 462.1$ minutes $\mathrm{p}=0.22$ ).

Table 3 shows the univariate and multivariate analysis for predictors of an $\mathrm{S} 2 \mathrm{P}$ time $>90$ minutes. Among 9 variables examined, female sex (Odds Ratio: 2.46, 95\% CI 1.10-5.60 $\mathrm{P}=0.03$ ), subjective opinion that the event was not an AMI (Odds Ratio 2.44, 95\% CI 1.20-5.0, $\mathrm{P}=0.01$ ) and level of education less than high school
(Odds ratio 7.21 95\% CI 1.59-32.75 $\mathrm{P}=0.01$ ) were independent predictors for S2P time $>90$ minutes.

\section{Discussion}

It is widely known that women have longer S2P times compared to men. $5,6,8,9,12,16,17,23,24,26,27$ Some hypotheses to explain this finding have been proposed. Studies have shown that women experience more atypical symptoms than men ${ }^{22,28-30,32}$ while older studies have reported that women are more likely than men to consult with their doctors or call family or friends before going to the hospital. ${ }^{33}$ A meta-synthesis by Lefler at $\mathrm{al}^{31}$ was able to analyze multiple descriptive studies that might explain these differences but none of these studies provided the same focus as the current study: We focused on STEMI, symptoms, socieconomic variables and detailed analysis of thoughts prior to arrival. Many of the studies which have explored the reasons for delay to presentation in women and men with AMI have been performed at a time prior to the introduction of the Red Dress Campaign, and prior to the institution of Mission: Lifeline, both of which have placed a greater emphasis on timely presentation and reperfusion for patients with STEMI. Our study provides a detailed analysis of the thought processes and patterns of behavior of patients with AMI and to our knowledge is the largest study to specifically look at patterns of behavior in patients of all ages with STEMI undergoing primary PCI, thus enabling us to determine which psycho-social factors contributed to a delayed presentation. We demonstrated that women were more likely than men to have atypical symptoms, and women were less likely than men to recognize that their symptoms were due to an AMI. Furthermore, prior to coming to the hospital, women were more likely to call a family or friend, and there was a non-significantly lower proportion of women who called 911 first, (before calling others). Despite this, female sex was still an independent predictor for a prolonged S2P time, indicating that other factors are contributing to prolonged delays. When sex was controlled in the multivariate analysis, the odds ratio for a prolonged S2P time for the variables "subjective opinion that the event was not an AMI" and "level of education (less than high school)" was increased compared to the univariate analysis. This increase in the magnitude of the effect of these variables after adjusting for sex, suggests that these variables may be responsible in part for some of the difference initially noted in women and men. 
Table 3 Univariate and Multivariate Predictors of S2P Time $>90$ Minutes

\begin{tabular}{|c|c|c|c|c|}
\hline \multirow[t]{2}{*}{ Variables } & \multicolumn{2}{|c|}{ Univariate Analysis } & \multicolumn{2}{|c|}{ Multivariate Analysis } \\
\hline & Odds Ratio (95\% Cl) & p value & Odds Ratio $(95 \% \mathrm{Cl})$ & p value \\
\hline Age -years & $1.01(0.99-1.03)$ & 0.23 & $1.01(0.98-1.03)$ & 0.60 \\
\hline Female Sex & $2.31(1.16-4.59)$ & 0.02 & $2.46(1.10-5.60)$ & 0.03 \\
\hline White Race (vs Black or other races) & $0.91(0.51-1.62)$ & 0.76 & $1.27(0.66-2.47)$ & 0.47 \\
\hline Diabetes mellitus & $0.72(0.34-1.52)$ & 0.39 & $0.55(0.23-1.29)$ & 0.17 \\
\hline \multicolumn{5}{|l|}{ Education } \\
\hline \multicolumn{5}{|l|}{ College and above (ref) } \\
\hline At least high school diploma & $4.43(1.14-17.29)$ & 0.03 & $3.58(0.83-15.42)$ & 0.09 \\
\hline Less than high school & $4.97(1.25-19.71)$ & 0.02 & $7.21(1.59-32.75)$ & 0.01 \\
\hline Insured & $0.69(0.28-1.70)$ & 0.42 & $0.48(1.18-1.30)$ & 0.15 \\
\hline \multicolumn{5}{|l|}{ Employment } \\
\hline \multicolumn{5}{|l|}{ Employed (ref) } \\
\hline Unemployed & $1.54(0.75-3.17)$ & 0.24 & $1.57(0.68-3.63)$ & 0.30 \\
\hline Retired/disabled & $1.26(0.67-2.38)$ & 0.47 & $1.30(0.54-3.15)$ & 0.56 \\
\hline Atypical symptoms & $0.93(0.53-1.62)$ & 0.79 & $0.68(0.35-1.34)$ & 0.27 \\
\hline Subjective opinion event was not an AMI & $1.82(1.00-3.33)$ & 0.05 & $2.44(1.20-5.00)$ & 0.01 \\
\hline
\end{tabular}

Abbreviation: AMI, Acute Myocardial Infarction.

An analysis of the Variation in Recovery: Role of Gender on Outcomes of Young AMI Patients (VIRGO) ${ }^{34}$ study examined 2985 women and men $\leq 55$ years of age presenting with an AMI in the USA, and also assessed through detailed interviews a patient's perception of symptoms. This is the largest registry of young women and men with AMI to contain detailed information about demographic and psycho-social factors. In this study, the authors demonstrated that as compared to men, a larger proportion of women had atypical symptoms. While there was no significant difference in the proportion of women and men that perceived their symptoms as "heart related", women were less likely than men to eventually seek medical care due to concerns about a "heart problem". As in our study, a larger proportion of women than men in VIRGO had a delay from symptom onset to hospital presentation. It is noteworthy that there are important differences in the clinical characteristics of the study participants between the VIRGO study and the current report. (female vs male enrollment: 2:1 vs 1:3; mean age, women/men: 47.2 years/47.1 years vs 68.7 years/ 60.7 years; \% Hispanic, women/men: $7.6 \% / 8.4 \%$ vs $32 \% /$ $25 \%$; $\%$ of patients with STEMI, women/men: $45.9 \% /$ $57.7 \%$ vs $100 \% / 100 \%$ ). Despite this, it is interesting to note that both studies reported very similar findings.
Therefore, our study, further contributes to the literature by demonstrating that even among a more diverse population of patients with STEMI, women are more likely than men to have atypical symptoms and do not recognize that their symptoms are a result of an AMI.

We noted that a large number of women delayed in seeking medical care because they did not think the event was an AMI. This has been shown in earlier reports. ${ }^{34-36}$ Symptom recognition is related to the quality and intensity of symptom onset, with gradual and vague symptoms, being interpreted as "not the heart". ${ }^{35,36,37}$ This is important, because, "belief that one is having a heart attack" is associated with shorter delays to hospital presentation. ${ }^{22,38}$ This "belief that one is having a heart attack" is likely influenced by recognition of one's symptoms, as well as recognition of one's potential for developing a heart attack. ${ }^{36,39}$ Over the past 20 years, there have been considerable efforts aimed at raising awareness of heart disease in women through educational campaigns including the Red Dress Campaign and the NHLBI Heart Truth. Although awareness of heart disease and related risk factors have improved as a result of these efforts, only a minority of women recognize the atypical symptoms that can be seen in a myocardial infarction; ${ }^{40}$ In a survey distributed to 2342 women across the United States, ${ }^{40}$ only 
$18 \%$ and $38 \%$ of responders correctly reported nausea, or shortness of breath as a symptom of a heart attack respectively. This lack of awareness despite outreach efforts is further evidenced by the lack of improvement in time to presentation in women over the years. ${ }^{6}$ Furthermore, in the VIRGO study, ${ }^{39}$ nearly all patients $(98 \%)$ had at least one cardiac risk factor, and approximately $2 / 3$ of patients had 3 or more risk factors. Despite this, only half of the patients with AMI had considered themselves "at risk" for heart disease before their incident event, and less than half of patients were informed by their health care provider that they were at risk, and/or were advised counseling regarding risk reduction.

Once symptoms are recognized as serious, taking action to get help for these symptoms is also an important step to achieving timely care. ${ }^{41,42}$ When symptoms occur patients are encouraged to call 911, as the use of 911 services improves outcomes. Women have been shown to take longer to act upon symptoms and are more likely than men to delay in calling for help due to a concern about "troubling others". 38 On the contrary, studies have shown that women with AMI are more likely than men to call 911. ${ }^{43,44}$ Despite this the contact to device times is significantly longer for women than men. ${ }^{14,45}$ In our study, although it appeared that an equal proportion of women and men were transported to the hospital using emergency medical services, we were unable to obtain the time of first medical contact and thus we were unable to determine whether the emergency medical services field times also contributed to the longer delays noted in women.

While the most commonly discussed reasons for delay relates to recognition of symptoms, and the decision to call 911, there may be other factors affecting delay. Insurance and financial concerns have also been shown to influence prehospital delays. ${ }^{15,46}$ Although we demonstrated a similar proportion of women and men who had insurance, it is possible that the type of health insurance held by the patients in our study, (and thus the remaining deductible or residual cost of the hospital care), differed between women and men, thus influencing the decision to seek medical care.

We demonstrated that a lower proportion of women as compared to men had achieved a higher level of education. Furthermore, our multivariate analysis showed that level of education (high school diploma or greater vs none) was a significant independent predictor of S2P time $>90$ minutes. The VIRGO trial ${ }^{34}$ also demonstrated an association with level of education and delays from symptom onset to hospital presentation. It is possible that a larger proportion of the population not achieving a high school diploma are illiterate, and/or unfamiliar with the use of current technology, and thus do not avail themselves to the newest educational campaigns on heart disease. It is for this reason that community outreach in the form of direct inperson education, and, the use of diverse types of advertising including radio and television advertisements as well as web-based and social media platforms should be considered to reach a larger proportion of the population.

\section{Limitations}

Our study has a few limitations. 1) We include only those patients with STEMI who received primary PCI and who were available for and consented to the additional questions. Late presenters and medically treated patients were not included in this analysis. Since women are more likely to present outside of the time window for reperfusion therapy, (and thus receive conservative treatment), one would expect that the inclusion of the medically treated patients in the study would only have strengthened our findings. Additionally, it is possible that the inclusion of only those patients who were able to and willing to participate in the study may have resulted in selection bias and influenced the results of the study. 2) Although the time of symptom onset was prospectively obtained and recorded in the chart at the time of the initial hospital encounter, the time of symptom onset was subjective, and based on the patient's report at the time of admission. It is possible that there were differences in the recollection and reporting of symptoms that could not be accounted for in our study. 3) Although baseline clinical variables and symptom onset time were prospectively recorded, the interview took place at a time remote from the hospitalization for the STEMI. Therefore, the reporting of a patient's thoughts and responses at the time of the infarct was based on the patients recollection of the events, and may have differed in retrospect from their actual thoughts and actions. 4) We did not have data on long term follow up for these patients, and hence it is unclear if the longer delays affected patient's clinical outcome.

\section{Conclusions}

Compared to men, women with AMI have longer prehospital delays. The longer delays are associated with a higher prevalence of atypical symptoms, and a lack of belief in women that they are having an AMI. Additionally, 
longer pre-hospital delays were seen in patients with a lower level of education and patients who did not think they were having an AMI. The results of this analysis suggest a continued need to educate our communities. Consideration should be given to expand educational efforts to radio and TV ads, or direct "in-person" educational outreach programs as well as web-based and social media platforms. This diverse approach to raise awareness will likely influence a larger population of patients at risk. Educational campaigns should emphasize the importance of recognizing both typical and atypical symptoms of AMI in women and men, and highlight the importance of acting quickly and calling 911 once symptoms develop.

\section{Acknowlegements}

The authors wish to acknowledge the following people who supported our efforts in conducting some of the interviews and/or identifying cases for data collection: Kathleen Kearney, RN, Vladimir Fridman, MD, and Mariusz Wysoczanski, MD. The abstract of this paper was presented at the American Heart Association Quality of Care and Outcomes Meeting and the World Congress of Heart Disease Meeting (A joint meeting) as a poster presentation with interim findings. Our work has otherwise not been published in any form.

\section{Disclosure}

The authors report no conflicts of interest in this work.

\section{References}

1. O'Gara PT, Kushner FG, Ascheim DD; American College of Cardiology Foundation/American Heart Association Task Force on Practice Guidelines. 2013 ACCF/AHA guideline for the management of ST-elevation myocardial infarction: a report of the American College of Cardiology Foundation/American Heart Association Task Force on Practice Guidelines. Circulation. 2013;127(4):e362-425. doi:10.1161/CIR.0b013e3182742c84

2. Jollis JG, Al-Khalidi HR, Monk L, et al.; Regional Approach to Cardiovascular Emergencies (RACE) Investigators. Expansion of a regional ST-segment-elevation myocardial infarction system to an entire state. Circulation. 2012;126(2):189-195. doi:10.1161/ CIRCULATIONAHA.111.068049

3. Jollis JG, Al-Khalidi HR, Roettig ML, Berger PB, Corbett CC, Doerfler SM. Impact of regionalization of ST-segment-elevation myocardial infarction care on treatment times and outcomes for emergency medical services-transported patients presenting to hospitals with percutaneous coronary intervention: mission: lifeline accelerator-2. Circulation. 2018;137(4):376-387.

4. Krumholz HM, Herrin J, Miller LE, et al. Improvements in door-toballoon time in the United States, 2005 to 2010. Circulation. 2011;124 (9):1038-1045. doi:10.1161/CIRCULATIONAHA.111.044107

5. Nguyen HL, Gore JM, Saczynski JS, et al. Age and sex differences and 20-year trends (1986 to 2005) in prehospital delay in patients hospitalized with acute myocardial infarction. Circ Cardiovasc Qual Outcomes. 2010;3 (6):590-598. doi:10.1161/CIRCOUTCOMES.110.957878
6. Diercks DB, Owen KP, Kontos MC. Gender differences in time to presentation for myocardial infarction before and after a national women's cardiovascular awareness campaign: a temporal analysis from the Can Rapid Risk Stratification of Unstable Angina Patients Suppress ADverse Outcomes with Early Implementation (CRUSADE) and the National Cardiovascular Data Registry Acute Coronary Treatment and Intervention Outcomes Network-Get with the Guidelines (NCDR ACTION registry-GWTG). Am Heart J. 2010;160(1):80-7.e3. doi:10.1016/j.ahj.2010.04.017

7. Saczynski JS, Yarzebski J, Lessard D, et al. Trends in prehospital delay in patients with acute myocardial infarction (from the Worcester Heart Attack Study). Am $J$ Cardiol. 2008;102 (12):1589-1594. doi:10.1016/j.amjcard.2008.07.056

8. Goldberg RJ, Gurwitz JH, Gore JM. Duration of, and temporal trends (1994-1997) in, prehospital delay in patients with acute myocardial infarction: the second National Registry of Myocardial Infarction. Arch Intern Med. 1999;159(18):2141-2147. doi:10.1001/ archinte.159.18.2141

9. Chandrasekhar J, Marley P, Allada C, et al. Symptom-to-balloon time is a strong predictor of adverse events following primary percutaneous coronary intervention: results from the australian capital territory PCI registry. Heart Lung Circ. 2017;26(1):41-48. doi:10.1016/j. hlc.2016.05.114

10. De Luca G, Suryapranata H, Zijlstra F; ZWOLLE Myocardial Infarction Study Group. Symptom-onset-to-balloon time and mortality in patients with acute myocardial infarction treated by primary angioplasty. J Am Coll Cardiol. 2003;42(6):991-997. doi:10.1016/ S0735-1097(03)00919-7

11. Gibson CM, Murphy SA, Kirtane AJ; TIMI Study Group. Association of duration of symptoms at presentation with angiographic and clinical outcomes after fibrinolytic therapy in patients with ST-segment elevation myocardial infarction. $J$ Am Coll Cardiol. 2004;44(5):980-987. doi:10.1016/j.jacc.2004.05.059

12. Newby LK, Rutsch WR, Califf RM, et al. Time from symptom onset to treatment and outcomes after thrombolytic therapy. GUSTO-1 Investigators. $J$ Am Coll Cardiol. 1996;27(7):1646-1655. doi:10.1016/0735-1097(96)00053-8

13. Berger PB, Ellis SG, Holmes DR, et al. Relationship between delay in performing direct coronary angioplasty and early clinical outcome in patients with acute myocardial infarction: results from the global use of strategies to open occluded arteries in acute coronary syndromes (GUSTO-IIb) trial. Circulation. 1999;100(1):14-20. doi:10.1161/01.CIR.100.1.14

14. Roswell RO, Kunkes J, Chen AY, et al. Impact of sex and contact-todevice time on clinical outcomes in acute ST-segment elevation myocardial infarction-findings from the national cardiovascular data registry. $J$ Am Heart Assoc. 2017;6(1). doi:10.1161/JAHA.116.004521

15. Ting HH, Bradley EH, Wang Y. Delay in presentation and reperfusion therapy in ST-elevation myocardial infarction. Am J Med. 2008;121(4):316-323. doi:10.1016/j.amjmed.2007.11.017

16. Smolderen KG, Spertus JA, Nallamothu BK. Health care insurance, financial concerns in accessing care, and delays to hospital presentation in acute myocardial infarction. JAMA. 2010;303(14):1392-1400. doi:10.1001/jama.2010.409

17. Sheifer SE, Rathore SS, Gersh BJ. Time to presentation with acute myocardial infarction in the elderly: associations with race, sex, and socioeconomic characteristics. Circulation. 2000;102 (14):1651-1656. doi:10.1161/01.CIR.102.14.1651

18. Meischke H, Larsen MP, Eisenberg MS. Gender differences in reported symptoms for acute myocardial infarction: impact on prehospital delay time interval. Am J Emerg Med. 1998;16(4):363-366. doi:10.1016/S0735-6757(98)90128-0

19. Park YH, Kang GH, Song BG, et al. Factors related to prehospital time delay in acute ST-segment elevation myocardial infarction. J Korean Med Sci. 2012;27(8):864-869. doi:10.3346/jkms.2012.27.8.864 
20. Goff DC Jr, Feldman HA, McGovern PG, et al. Prehospital delay in patients hospitalized with heart attack symptoms in the United States: the REACT trial. Am Heart J. 1999;138(6 Pt 1):1046-1057. doi:10.1016/S0002-8703(99)70069-4

21. Goldberg RJ, Yarzebski J, Lessard D, Gore JM. Decade-long trends and factors associated with time to hospital presentation in patients with acute myocardial infarction: the Worcester Heart Attack study. Arch Intern Med. 2000;160(21):3217-3223. doi:10.1001/ archinte.160.21.3217

22. Guzman LA, Li S, Wang TY, et al. Differences in treatment patterns and outcomes between Hispanics and non-Hispanic Whites treated for ST-segment elevation myocardial infarction: results from the NCDR ACTION Registry-GWTG. J Am Coll Cardiol. 2012;59 (6):630-631. doi:10.1016/j.jacc.2011.10.882

23. Clark LT, Bellam SV, Shah AH, Feldman JG. Analysis of prehospital delay among inner-city patients with symptoms of myocardial infarction: implications for therapeutic intervention. J Natl Med Assoc. 1992;84(11):931-937.

24. Cannon CP, Gibson CM, Lambrew CT, et al. Relationship of symptom-onset-to-balloon time and door-to-balloon time with mortality in patients undergoing angioplasty for acute myocardial infarction. JAMA. 2000;283(22):2941-2947. doi:10.1001/ jama.283.22.2941

25. Chen SI, Wang Y, Dreyer R, et al. Insurance and prehospital delay in patients $</=55$ years with acute myocardial infarction. Am J Cardiol. 2015;116(12):1827-1832. doi:10.1016/j.amjcard.2015.09.018

26. Heer T, Schiele R, Schneider S, et al. Gender differences in acute myocardial infarction in the era of reperfusion (the MITRA registry). Am J Cardiol. 2002;89(5):511-517. doi:10.1016/S0002-9149(01)02289-5

27. Jäger B, Farhan S, Rohla M, et al.; Vienna STEMI Registry Group. Clinical predictors of patient related delay in the Vienna ST-elevation myocardial infarction network and impact on long-term mortality. Eur Heart J Acute Cardiovasc Care. 2017;6(3):254-261. doi:10.1177/2048872616633882

28. Vaccarino V, Parsons L, Every NR, Barron HV, Krumholz HM. Sexbased differences in early mortality after myocardial infarction. National registry of myocardial infarction 2 participants. $N$ Engl J Med. 1999;341(4):217-225. doi:10.1056/NEJM199907223410401

29. De Luca G, Suryapranata H, Dambrink JH, Ottervanger JP. Sexrelated differences in outcome after ST-segment elevation myocardial infarction treated by primary angioplasty: data from the Zwolle Myocardial Infarction study. Am Heart J. 2004;148:852-856. doi:10.1016/j.ahj.2004.05.018

30. Dey SF, Devlin G, Devlin G, et al. Sex-related differences in the presentation, treatment and outcomes among patients with acute coronary syndromes: the Global Registry of Acute Coronary Events. Heart. 2009;95:20-26. doi:10.1136/hrt.2007.138537

31. Lefler LL, Bondy KN. Women's delay in seeking treatment with myocardial infarction: a meta-synthesis. $J$ Cardiovasc Nurs. 2004;19(4):251-268. doi:10.1097/00005082-200407000-00005

32. Canto JG, Rogers WJ, Goldberg RJ, et al.; NRMI inestigators. Association of age and sex with myocardial infarction symptom presentation and in-hospital mortality. JAMA. 2012;307(8):813-822. doi:10.1001/jama.2012.199

33. Tunstall-Pedoe H, Morrison C, Woodward M, Fitzpatrick B, Watt G. Sex differences in myocardial infarction and coronary deaths in the Scottish MONICA population of Glasgow 1985 to 1991. Presentation, diagnosis, treatment, and 28-day case fatality of 3991 events in men and 1551 events in women. Circulation. 1996;93 (11):1981-1992. doi:10.1161/01.CIR.93.11.1981
34. Lichtman JH, Leifheit EC, Safdar B, et al. Sex differences in the presentation and perception of symptoms among young patients with myocardial infarction: evidence from the VIRGO study (variation in recovery: role of gender on outcomes of young AMI patients). Circulation. 2018;137(8):781-790. doi:10.1161/CIRCULATIONAHA.117.031650

35. Leslie WS, Urie A, Hooper J, Morrison CE. Delay in calling for help during myocardial infarction: reasons for the delay and subsequent pattern of accessing care. Heart. 2000;84(2):137-141. doi:10.1136/ heart.84.2.137

36. Lichtman JH, Leifheit-Limson EC, Watanabe E, et al. Symptom recognition and healthcare experiences of young women with acute myocardial infarction. Circ Cardiovasc Qual Outcomes. 2015;8(2 Suppl 1):S31-8. doi:10.1161/CIRCOUTCOMES.114.001612

37. Davis LL. A qualitative study of symptom experiences of women with acute coronary syndrome. J Cardiovasc Nurs. 2017;32 (5):488-495. doi:10.1097/JCN.0000000000000381

38. Moser DK, McKinley S, Dracup K, Chung ML. Gender differences in reasons patients delay in seeking treatment for acute myocardial infarction symptoms. Patient Educ Couns. 2005;56(1):45-54. doi:10.1016/j.pec.2003.11.011

39. Leifheit-Limson EC, D’Onofrio G, Daneshvar M, et al. Sex differences in cardiac risk factors, perceived risk, and health care provider discussion of risk and risk modification among young patients with acute myocardial infarction: the VIRGO Study. $J$ Am Coll Cardiol. 2015;66(18):1949-1957. doi:10.1016/j.jacc.2015.08.859

40. Mosca L, Hammond G, Mochari-Greenberger H, Towfighi A, Albert Ma; American Heart Association Cardiovascular Disease and Stroke in Women and Special Populations Committee of the Council on Clinical Cardiology, Council on Epidemiology and Prevention, Council on Cardiovascular Nursing, Council on High Bloo. Fifteen-year trends in awareness of heart disease in women: results of a 2012 American Heart Association national survey. Circulation. 2013;127(11):1254-63, e1-29. doi:10.1161/CIR.0b01 $3 \mathrm{e} 318287 \mathrm{cf} 2 \mathrm{f}$

41. Bouma J, Broer J, Bleeker J, van Sonderen E, Meyboom-de Jong B, DeJongste MJ. Longer pre-hospital delay in acute myocardial infarction in women because of longer doctor decision time. $J$ Epidemiol Community Health. 1999;53(8):459-464. doi:10.1136/jech.53.8.459

42. Rosenfeld AGLA, Darney BG. Understanding treatment-seeking delay in women with acute myocardial infarction: descriptions of decision-making patterns. Am $J$ Critical Care Med. 2005;14:285-293. doi:10.4037/ajcc2005.14.4.285

43. McGinn AP, Rosamond WD, Goff DC Jr, Taylor HA, Miles JS, Chambless L. Trends in prehospital delay time and use of emergency medical services for acute myocardial infarction: experience in 4 US communities from 1987-2000. Am Heart J. 2005;150(3):392-400. doi:10.1016/j.ahj.2005.03.064

44. Newman JD, Davidson KW, Ye S, Shaffer JA, Shimbo D, Muntner P. Gender differences in calls to 9-1-1 during an acute coronary syndrome. Am J Cardiol. 2013;111(1):58-62. doi:10.1016/j. amjcard.2012.08.048

45. Aguilar SA, Patel M, Castillo E, et al. Gender differences in scene time, transport time, and total scene to hospital arrival time determined by the use of a prehospital electrocardiogram in patients with complaint of chest pain. J Emerg Med. 2012;43(2):291-297. doi:10.1016/j.jemermed.2011.06.130

46. Foraker RE, Rose KM, McGinn AP, et al. Neighborhood income, health insurance, and prehospital delay for myocardial infarction: the atherosclerosis risk in communities study. Arch Intern Med. 2008;168 (17):1874-1879. doi:10.1001/archinte.168.17.1874 


\section{Publish your work in this journal}

Therapeutics and Clinical Risk Management is an international, peerreviewed journal of clinical therapeutics and risk management, focusing on concise rapid reporting of clinical studies in all therapeutic areas, outcomes, safety, and programs for the effective, safe, and sustained use of medicines. This journal is indexed on PubMed Central, CAS,
EMBase, Scopus and the Elsevier Bibliographic databases. The manuscript management system is completely online and includes a very quick and fair peer-review system, which is all easy to use Visit http://www.dovepress.com/testimonials.php to read real quotes from published authors.

Submit your manuscript here: https://www.dovepress.com/therapeutics-and-clinical-risk-management-journal 